\title{
Main Features of Advanced Technology Industries in Lithuania
}

\author{
Dr. Asta Saboniene \\ Department of Economics, Kaunas University of Technology, Lithuania; asta.saboniene@ktu.lt \\ Dr. Daiva Laskiene
}

Department of Economics, Kaunas University of Technology, Lithuania; daiva.laskiene@ktu.It

\author{
Doi:10.5901/mjss.2015.v6n6s1p158
}

\begin{abstract}
The process of Lithuanian economics transformation underwent the evident shifts of manufacturing industry's structure having faced the drastic decline of demand for produced commodities after 1991. The traditional sectors were more flexible to adapt to changes of market demand, thus, they became prevailing Lithuanian industry's sectors distinguished by low technological susceptibility. Nevertheless, the development of advanced technology industries in Lithuania still remains an actual and relevant scientific issue. The practice of foreign countries' economic development reveals the role of advanced technology industries, which are expected to play an important part in the functioning and development of the economy. The competitive abilities of advanced technology industries are facilitated by stimulating the progress of science, technique and innovations, sustaining the investment into the scientific research on new products and technology renovations. The aim of the article is to reveal the main features of the performance of Lithuanian advanced technology industries and analyse the changes of the main indicators which make up the profile of these industries. However, the empirical study revealed that development of advanced technologies in Lithuania, except chemical industry, is still a slow process, thus, the issue considering their potential remains an actual problem.
\end{abstract}

Keywords: industry, advanced technologies, competitiveness.

\section{Introduction}

Advanced technology industries, in the form of the spread of $R \& D$, knowledge and innovation, reward their marginal social benefit to economics. Advanced technology industries are key manufacturing industries, which are expected to play a significant part in the development of the economics now and in the future. Aerospace, electronics, biology, nuclear energy and advanced engineering sectors belong to the category of industries that are marked by the intensively researched future development.

While advanced technologies make a relatively small share in the structure of Lithuanian manufacturing industry, this fact does not constitute a reason to assume that the issues of high-tech development are not relevant or important. Estimation of the development opportunities in high and medium-high technology manufacturing industries as well as the analysis of the basic indicators of these industries can be considered as a significant problem of the research. Nevertheless, the analysis of the scientific literature proposes that the outcomes of the performance of Lithuanian high technology industries as well as the results of the foreign trade have not been profoundly analysed, and the changes of the key indicators have not been duly substantiated. The previous analysis of Lithuanian exports structure, applying Factor inputs taxonomy, revealed the low share of technology driven and marketing driven industries (Saboniene, 2014). This article presents the analysis of the performance of advanced technology industries in Lithuania, conducting the problems in the context of economic integration in the EU, globalization and changing economic conditions.

The aim of the research paper is to reveal the main features of the performance of Lithuanian advanced technology industries and analyse the changes of their indicators in the context of economic integration. The object of the scientific research is the sector of advanced technologies in Lithuanian manufacturing industry.

The paper has been organized as follows: the first part outlines the theoretical basis of the main indicators employed to characterise the actual performance of the selected industries. The changes of the main indicators and benchmarking of high-tech and medium-high industries have been presented in the second part. The paper concludes with presentation of the summary of the results. 


\section{Literature Review and Methodology}

Scientific publications and empirical studies discuss the impact of R\&D and innovations on the development of hightechnology industries as the key drivers of country's economic growth (Hitiris 1998, Geroski 1989, Ericson 1998, Jalava, Pohjola 2002, Christensen et al. 2004, Chesbrough, Crowther 2006, Falk 2007, Bravo-Ortega 2011, Wang et al. 2013). Curzon Price (1990) pointed out the importance of high-tech stimulation by reducing market failures such as risks and costs of innovations or prevention of the R\&D and innovation activity duplication, particularly in the field of R\&D and environmental damage. Bennett (1997) states that the "benefits, arising from R\&D, including improvements in the technical aspects of existing products, introduction of new products as well as lower costs of production, national government grants and subsidies for R\&D, play a crucial role in investment decisions". Thus, the cause to heighten advanced industries is their large technological contribution to the whole economy, characterised by the abilities to create and apply innovations, modern information technologies and improve managerial qualification and creativity.

In order to evaluate the performance of the advanced technology industries and consider the changes emerging in these industries, it is necessary to analyse a set of the main characteristics. The empirical analysis allows to define the direction of the structural changes over the period of 2004-2012 and to make the judgment on structural significance of advanced industries.

The prime characteristics of the actual performance of an individual industry are the indicators of production sales and exports share. The rates of export share in total export and export growth provide the information on the demand conditions and are considered to be important indicators for evaluation of the potential of an individual industry. Sectoral export intensity is a ratio, which compares the shares of export and production sales in order to evaluate the abilities of the industries to produce goods for global market. Export share compared to output share can also provide the signals of the shifts in strengthening or weakening competitive positions in international markets. The empirical study employed the data of export of Lithuanian origin goods for a precise evaluation of the results of export performance.

Productivity often serves as a key indicator of the performance of particular industry and, according to Buckley et al. (1988), it also describes the competitiveness of industries or individual firms. Productivity measures analyse the relationship between output (produced goods and services) and input (used resources) (Henricsson et al. 2005). Valueadded generated in an economy is the main criterion of economic performance. A commonly used and relatively straightforward measure of productivity is the value-added per employee, where it equates the difference between the income and costs generated from the sales of the goods and services, supplied by individual industries. This indicator exposes the ability of an industry to generate value-added production, employing resources in the most efficient and productive way possible. According to Tikhomirova (1997), it seems feasible to benchmark each manufacturing industry according to the highest level of value-added per employee achieved at a particular time.

The significant indicator of industry performance is an average wage per employee. The industries, associated with high value-added, also provide higher levels of income and wages. The usage of average wage indicator is based on understanding that the higher level of wages in different manufacturing industries indicates the demand for higher employee skills and indirectly presents the potential associated with staff creativity, competences and creation of higher value-added.

The indicator of foreign direct investment is also included in benchmarking in order to demonstrate the attractiveness of Lithuanian advanced industries by taking into account the significance of foreign capital to the economy. FDI promotes the industrial development as it enables making products by employing new technologies, transferring the cutting-edge and know-how knowledge, creating new value-added and new work places. Despite the different opinions of scholars regarding positive and negative impacts of FDI on host countries, the amounts of FDI in transition economy industries still remain of high importance.

Finally, the empirical study includes the indicator of R\&D intensity as an important criterion for the development of individual industries, providing information on the degree of the sophistication of an industrial output and of the knowledge embodied in the goods produced. $R \& D$ intensity is measured as a percentage rate, which enables to compare the $R \& D$ expenditures to the sales of an individual manufacturing industry. Advanced industries, which are often characterized by economies of scale and imperfect competition, are engaged in the activities that require large expenditures on R\&D for pioneering and technology improvement.

All the indicators together make up a profile of an individual manufacturing industry and reflect the variety of the competitiveness-related facets; forasmuch, the low level of several indicators can reveal the problem, which emerges in a particular sector, since it enables to evaluate the actual performance of the sector in a long-term period. The benchmarking covers nineteen manufacturing industries; the indicators and ranks were calculated for the three year period in order to eliminate the influence of annual fluctuations. Aiming to assess overall composite ranks, the 
manufacturing industries were ranked by each indicator, and higher value of an indicator was associated with higher value of the rank. Thus, the overall composite rank was calculated as an average of all the indicators' ranks.

The other methods of the scientific research employed in this study include the analysis of the scientific literature, the comparative analysis of the statistical data and mathematic calculations.

\section{Results}

The development of advanced technology industries has important implications on the country's industrial competitiveness and evaluation of its economic level; thus, they still compose the most important EU economic sector for production, trade and employment. According to common opinion, the countries, having the basic part of medium-low and low-technology industries in their industrial structure, cannot be regarded as having achieved a high economic level. In the case of Lithuania, the traditional industrial sectors with low and medium-low technological susceptibility prevail and their significance is obvious. On the other hand, stimulation of the growth of the relatively high-value added production is an important factor for improving industrial development in the future while the competitiveness might be increased by higher value-added, higher-skilled labour and science-intensive industries as well as by intensive transition to knowledgedriven economy. Following the practice of the advanced countries, the strategies of foreign direct investment attraction, innovation activity promotion, competitive ability formation and intensification, sponsorship for education and science, implementation of scientific research results and technologies are most relevant drivers of industrial development.

With reference to the data of Eurostat, Lithuanian high-tech exports indicator, calculated as the share of all hightech products export in total exports, made 5.8 per cent in 2012 and formed the slim share in comparison to other EU states (see Figure 1).

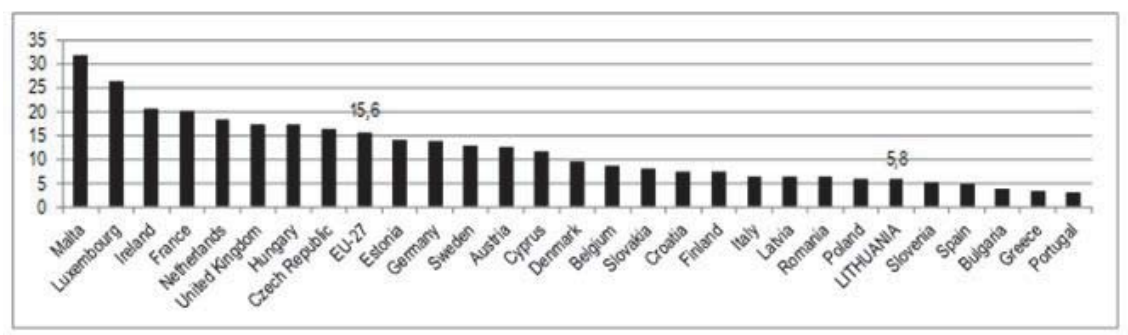

Figure. 1. The share of high-tech exports, per cent, 2012.

Source: the data of Eurostat. High Technology products are defined as the sum of the following products: Aerospace, Computers-office machines, Electronics-telecommunications, Pharmacy, Scientific instruments, Electrical machinery, Chemistry, Non-electrical machinery, Armament.

In order to look over the high-tech and medium high-tech industries' status in Lithuania, it is purposeful to assess the structure of industrial sales, referring to OECD classification of manufacturing industries based on technology (see Table 1). Manufacture of computer, electronic and optical products, assigned to the group of high-tech category, made only 1.0 per cent of total production sales in Lithuanian manufacturing industry in 2013. During the period of $2004-2013$, the share of this sector declined more than fourfold. Manufacture of the basic pharmaceutical products and pharmaceutical preparations also made a slim share, which contributed to 0.6 per cent in 2013. 
Table 1. Structural changes of Lithuanian high-tech and medium high-tech industries by production sales in 2004-2013, per cent

\begin{tabular}{lccccccccccc}
\hline & $\mathbf{2 0 0 4} 2005$ & 2006 & 2007 & 2008 & 2009 & 2010 & 2011 & 2012 & $\mathbf{2 0 1 3}$ \\
\hline C Manufacturing & 100 & 100 & 100 & 100 & 100 & 100 & 100 & 100 & 100 & 100 \\
\hline $\begin{array}{l}\text { High-tech manufacturing industries } \\
\text { C21 Manufacture of basic pharmaceutical products and } \\
\text { pharmaceutical preparations }\end{array}$ & 0.4 & 0.3 & 0.3 & 0.3 & 0.2 & 0.3 & 0.5 & 0.4 & 0.4 & 0.6 \\
C26 Manufacture of computer, electronic and optical product & 4.6 & 3.3 & 2.7 & 2.2 & 1.3 & 1.8 & 1.7 & 1.2 & 1.1 & 1.0 \\
Medium-high manufacturing industries & & & & & & & & & & \\
C20 Manufacture of chemicals and chemical products & 5.0 & 5.4 & 6.4 & 10.9 & 11.9 & 10.6 & 10.9 & 11.7 & 11.5 & 10.2 \\
C27 Manufacture of electrical equipment & 1.8 & 1.7 & 1.7 & 1.6 & 1.4 & 1.1 & 1.1 & 1.1 & 1.4 & 1.5 \\
C28 Manufacture of machinery and equipment & 1.0 & 1.1 & 1.3 & 1.4 & 1.9 & 1.7 & 1.6 & 1.6 & 1.6 & 1.9 \\
C29 Manufacture of motor vehicles, trailers and semi-trailers & 2.3 & 1.8 & 1.7 & 1.8 & 1.3 & 0.5 & 0.7 & 0.8 & 0.8 & 1.0 \\
C30 Manufacture of other transport equipment & 1.1 & 1.1 & 0.9 & 1.0 & 0.9 & 1.2 & 1.0 & 0.5 & 0.7 & 0.8 \\
\hline
\end{tabular}

Source: calculated according to the data of The Department of Statistics to the Government of the Republic of Lithuania.

The sectors of medium complexity high technology industry, i.e. manufacture of motor vehicles, trailers and semi-trailers as well as manufacture of other transport equipment respectively made 1.0 and 0.8 per cent of whole the production in Lithuanian manufacture. Both industries showed the tendencies on production sales decrease. Manufacture of machinery and equipment retained their small shares in the structure of industry in $2004-2013$, with tendencies of modest growth from 1.1 to 1.9 per cent. Conversely, the share of electrical equipment manufacture slightly moved down and made 1.5 per cent in 2013. Finally, manufacture of chemicals and chemical products, assigned to the sector of medium high-tech technology industry, is one of the most promising sectors, taking a significant comparative share in the structure of production sales, considering the increase of its share from 5.0 per cent in 2004 to 10.2 per cent in 2013.

For the analysis of the performance of individual manufacturing industries, the separate indicators were used in order to highlight the problematic areas and get deeper insights in their particular characteristics, benchmarks, relative significance and hence their impact on the overall rank. The benchmarking of Lithuanian high-tech and medium-high industries was made by the values of the average rank of key indicators: export share in total state's exports, export growth, export intensity, value-added per employee, R\&D intensity, foreign direct investment and the level of average wage (Figure 2). A brief review on the results of the benchmarking of all the manufacturing industries revealed relative significance of the key characteristics to the analysed industries.

The industry C21 - Manufacture of basic pharmaceutical products and pharmaceutical preparations - is arguably among the most important industries in the developed countries, considering it as one of high-tech industries, in spite of the fact that it makes an extremely small share in sales and exports structure. The average rank of 12.1 placed this industry in the second position among nineteen industries since this industry achieved high ranks of R\&D intensity and average wage; thus, it demonstrated higher requirements for skills and qualifications of human resources. The high level of economic performance is proved by high indicators of value-added per employee and foreign direct investment. Nevertheless, despite the export growth, this industry seems to have a limited potential due to very low indices of export share and export intensity.

The industry C26 - Manufacture of computer, electronic and optical products - is in the focus of innovation and industrial policies in every developed economy. Despite relatively moderate rates of export performance as well as its share in industrial structure, this industry showed the high average rank of 11.4 and took the third position among nineteen industries due to the potential of R\&D and innovation performance as well as the combination of high level of average wage and value-added per employee, which reflects the demand of high requirements for qualifications of human resources. However, the development and potential of this industry is a problematic issue considering the declined share of its industrial sales during the period of 2004-2013.

C20 - Manufacture of chemicals and chemical products - achieved the high average rank of 15.6 and occupied the first place among nineteen industries due to relatively high values of value-added per employee, export share, average wage as well as on account of foreign direct investment inflows. The combination of high ranks of export shares and export growth enabled to achieve the leading position. This industry could be seen as one of the most significant and potential ones by the key indicators, notwithstanding, R\&D intensity rank was rather low.

The average rank retained its high value in comparison to the previous period. The average rank's value of C27 Manufacture of electrical equipment - visibly declined from 13.9 in 2003-2005 to 8.6 in 2009-2011. This industry is 
characterised by not large shares in industrial structure as well as exports. Attention should be drawn to the industry's moderate R\&D intensity and export intensity indicators, however, the value-added and FDI indicators are lower in comparison to the other ones. This makes it difficult to discuss about the future potential of $C 27$ without an in-depth qualitative analysis of individual companies.
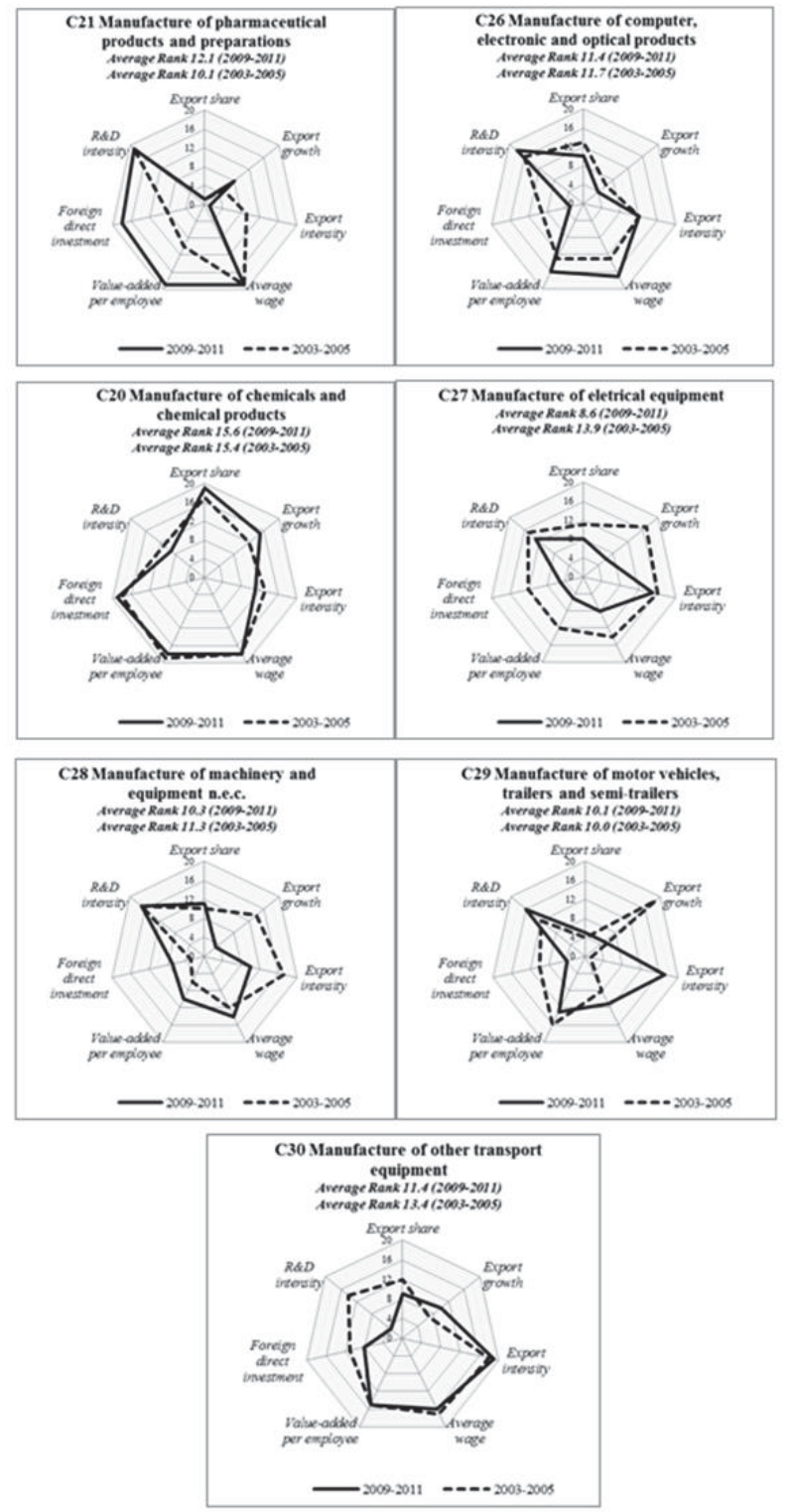

Figure 2. Benchmarking of Lithuanian high-tech (C21, C26) and medium high-tech (C20, C27, C28, C29, C30) industries C28 - Manufacture of machinery and equipment - attracts attention by its R\&D intensity rank and the moderate rank of export share, but this industry has a small share in industrial structure. The shrinkage of export growth was accompanied by the decreased rank of export intensity indicator. The slightly decreased average rank, established while comparing the two periods, limits the analysis of its future potential. 
C29 - Manufacture of motor vehicles, trailers and semi-trailers - also has small share in industrial structure but it can be characterised by increased R\&D intensity, export intensity and relatively sufficient indicator of value-added per employee. The ranks of foreign direct investment and export growth declined obviously in comparison to the previous period. However, the average rank retained its moderate value in the stable position due to the increased value of export intensity rank.

Finally, C30 - Manufacture of other transport equipment - achieved rather good indicators of export performance, but showed low rank of R\&D intensity, which declined visibly. Nevertheless, the value-added per employee and average wage ranks were relatively high, what is a remarkable feature proposing further development of this industry. Shipbuilding is a specific sector, considering the fierce competition from Asia producers, where this industry is treated as a priority sector supported by most of governments. European shipbuilding industries compete with cheaper labour countries, and efforts are directed towards the development of new technologies in order to resist the competitive pressures. Future performance of Lithuanian shipbuilding depends on production and demand of the specialised vessels. Anyway, the average rank of this industry moved down in the period of 2009-2011 in the comparison to the period of 2003-2005.

\section{The Concluding Remarks}

The relevance of the researched problem is based on the fact, that the shares of high-tech and medium-high industries in Lithuania are small and have declining trends except the manufacture of chemicals and chemical products. The set of the indicators was used to reveal the main features and shifts in advanced industries aiming at making up their profile and future trend. Changing the current industrial structure by increasing the shares of high and medium-high technology industries is not simple, and there are no clear tendencies of growth observed in Lithuanian industry within the analysed period.

Changing industrial structure by increasing the shares of high technology industries is a complex issue, especially minding the fact that the long-term results revealed the declined shares and indicators of Lithuanian high-tech industries. The main indicators of Lithuanian industrial companies such as value-added per employee, amount of attracted FDI, innovativeness and R\&D expenditures are relatively low in comparison to the ones in the EU. Overcoming of the factors that hamper innovation activities such as high innovation risk, high costs, lack of internal and external funding as well as lack of qualified personnel is a relevant problem for industrial companies, which implement innovations, including industrial research and technological work, at their own risk and discretion. Cooperation and strategic partnership between scientific institutions and industrial companies for creation and implementation of product and process innovations is still insufficient. Large investment into the scientific research, education and technologies is necessary to stimulate industrial progress; it also could be done by focusing the attempts on the secondary market of innovations improving already implemented products and technologies, targeting the industrial sectors that create bigger surplus value and so forth. The policy implications directed towards the creation of favourable business conditions for companies, promotion of high added-value activities and innovation activities have positive impact on the future development of advanced technology industries, however, it is important to keep in mind that the long-term changes are slow.

\section{References}

Bennett R., (1997). European Business. Pitman publishing MandE. Pearson Professional limited.

Bravo-Ortega, C. (2011). R\&D and Productivity: A Two Way Avenue? World Development. Volume 39, Issue 7, 1090-1107. http://dx.doi.org/10.1016/j.worlddev.2010.11.006.

Buckley, P. J., Pass, C. L., \& Prescott, K. (1988). Measures of international competitiveness: a critical survey. Journal of Management, $4(2), 175-200$.

Chesbrough, H., Crowther A., K. (2006). Beyond high tech: early adopters of open innovation in other industries. R\&D Management. Volume 36, Issue 3, 229-236. DOI: 10.1111/j.1467-9310.2006.00428.x.

Christensen, J.F., Olesen, M.H. \& Kjar, J.S. (2004). The industrial dynamics of open innovation-evidence from the transformation of consumer electronics. Working paper, Copenhagen Business School, Department of Industrial Economics and Strategy.

Curson Price, V. (1990). Competition and Industrial policies with emphasis on industrial policy. New York: St. Martins Press.

Falk, M. (2007). R\&D spending in the high-tech sector and economic growth. Research in Economics, Volume 61, Issue 3, 140-147. http://dx.doi.org/10.1016/j.rie.2007.05.002.

Geroski, P. (1989). European Industrial Policy and Industrial Policy in Europe. Oxford Review of Economic Policy, oxford. Washington, DC: American Psychological Association.

Henricsson, P., Ericsson, S. (2005). Measuring construction industry competitiveness: a holistic approach. A. C. Sidwell, Brisbane, Australia.

Hitiris, Th. (1998). European Union Economics. 4th edition. Prentice Hall Europe. 
Jalava, J., Pohjola, M. (2002) Economic growth in the New Economy: evidence from advanced economies. Information Economics and Policy. Volume 14, Issue 2, 189-210. http://dx.doi.org/10.1016/S0167-6245(01)00066-X.

Sabonienè, A. (2014). Quality mode of Lithuanian manufacturing industry's exports // Inžinerinè ekonomika = Engineering economics / Kaunas University of Technology. Kaunas: KTU. ISSN 1392-2785. 2014, Vol. 25, no. 4, p. 450-457. DOI: 10.5755/j01.ee. 25.4.6925

Tikhomirova, G. (1997). Analyzing changes in industry structure. CSES working paper, No. 11.

Wang, D. H-M., Yu, T. H-K., \& Liu, H-Q. (2013). Heterogeneous effect of high-tech industrial R\&D spending on economic growth. Journal of Business Research, Volume 66, Issue 10, 1990-1993. http://dx.doi.org/10.1016/j.jbusres.2013.02.023. 